\title{
Bite mark analysis in a case of child abuse
}

SADJ September 2019, Vol. 74 No. 8 p451 - p453

\author{
VM Phillips ${ }^{1}$, D Avelino
}

\section{CASE REPORT}

As the Forensic Odontology consultant of the Western Cape, I (VMP) was requested by a Lt. Col. of the South African Police Services to examine a child, NL, who was alleged to be a child abuse victim and who had bite marks on her body.

The examination took place at Karl Bremer Hospital, Bellville, in the Paediatric Ward. In attendance were the authors, a nursing sister, Lt. Col. and a Dt. Sgt of the SAPS. The assault on the child had taken place three weeks prior to the forensic odontology examination. According to the Police Officers there were three adults, two females, one male, and two children in the house at the time of the reported assault on the child.

The complainant ZP said the two children present were four years and six months of age respectively. These children did not undergo dental examination. The carer of the child UP was arrested as the possible perpetrator of the assault lesions on the child's body.

The Investigating Officer was requested to present the adults for dental examination at the Dental Faculty of the University of the Western Cape at Tygerberg. There were three females; ZP, UP and the biological mother $\mathrm{GL}$, as well as one male, GE.

Photographs were taken of the teeth of each adult and dental impressions were taken for comparison of their teeth with the bite marks. No dental impressions were necessary of ZP as she had no upper teeth. Each suspect signed an informed consent document with regard to the dental examination.

Author affiliations:

1. Vincent M Phillips: BDS, MChD, Dip Max-Facial Radiology, FC Path SA (Oral Path), PhD, DSc., Emeritus Professor, Department Oral and Maxillo-Facial Pathology and Forensic Science. Faculty of Health Sciences, University of the Western Cape.

ORCID Number: 0000-0003-1432-6274

2. Damiana Avelino: $B C h D, M S c$, Student in Department Oral and Maxillo-Facial Pathology and Forensic Science. Faculty of Health Sciences, University of the Western Cape.

ORCID Number: 0000-0002-2948-0779

Corresponding author: Vincent M Phillips

Department Oral and Maxillo-Facial Pathology and Forensic Science.

Faculty of Health Sciences, University of the Western Cape.

Tel: +27 (0)82 7257845

Email: vmphillips@uwc.ac.za

Author contributions:

1. Vincent M Phillips: Primary author - $60 \%$

2. Damiana Avelino: Secondary author $-40 \%$

\section{ACRONYMS \\ ABFO: American Board of Forensic Odontology}

\section{EXAMINATION OF THE CHILD VICTIM}

NL was a 2 year old child. She was wearing a 'nappy' and a hospital gown. The gown was removed for examination purposes and the child placed on a hospital examination bed. The authors examined the child's body for bite mark lesions.

Numerous lesions were seen on the back, abdomen and legs of the child. These lesions were judged to be in the late stages of healing and had left poorly distinctive bruises on the skin.

One of the lesions situated on the left abdomen was more visible and had defined healing puncture wounds corresponding to a bite mark (Fig. 1). The other lesions on the right side of the back and on the right leg were not well defined (Fig. 2), but were consistent with bite marks.

Photographs were taken of the lesions using a NIKON digital camera and an ABFO millimetre scale for size reference.

The various lesions on the skin of the child were relatively indistinct; some however showed definitive patterns of bite marks. The bite mark on the left abdomen (Fig. 2) was more noticeable and was used to investigate and to test correlation with the biting patterns of the adult suspects.

The sizes of the bite marks were consistent with adult dental arches and therefore the children could be dismissed as possible suspects.

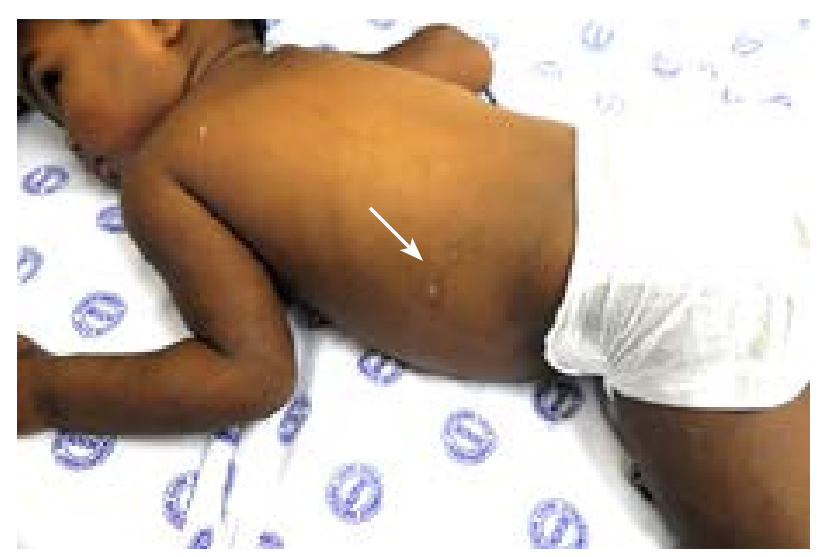

Figure 1. $A$ bite mark on the left abdomen of the victim. 


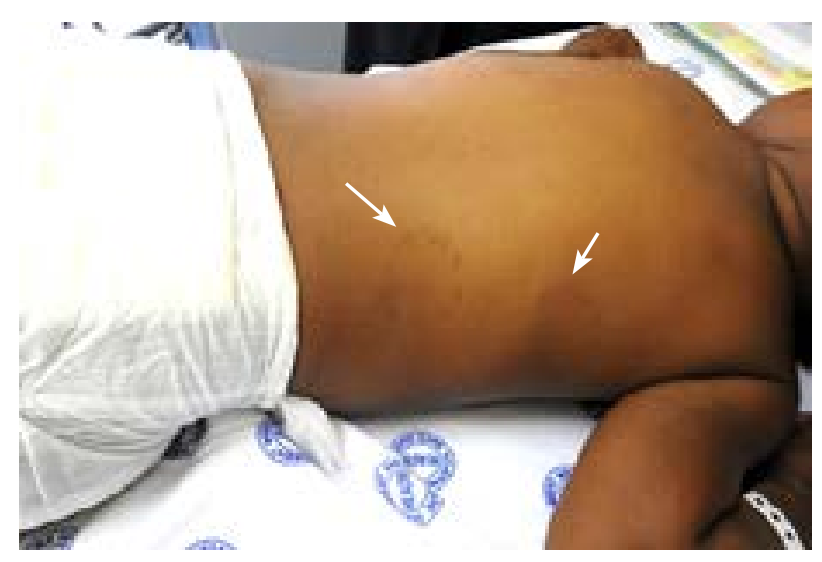

Figure 2. Two other bite marks on the right back of the victim. These were less distinct.

\section{Analysis of the bite mark}

Most of the bite marks on the body of the child were indistinct and in various stages of healing. The history of the assault showed that these lesions were approximately three weeks old during which the lesions had undergone healing.

One of the bite marks situated on the left abdomen of the child showed puncture wounds in stages of healing (Fig. 3). Between these puncture marks there was a faint curved pattern of bruises.

These puncture lesions were significant enough to analyse the biting patterns of the three adults and to facilitate correlation with the tracings of their upper and lower dental arches.

Only the upper teeth of the three suspects were investigated as the cause of the bite mark as the bruises due to the lower teeth were too indistinct.

Figure 3 shows the bite mark on the left abdomen with an ABFO scale in situ.

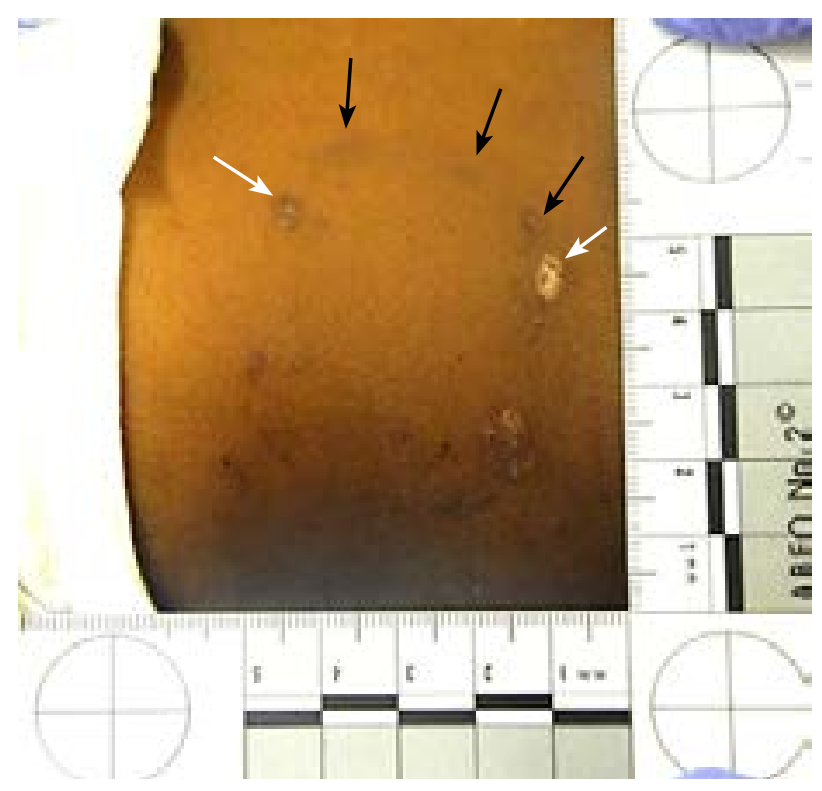

Figure 3. The bite mark on the left abdomen of the victim showing healing of the puncture wounds which were due to maxillary teeth (White arrows) and the indistinct curved bruise pattern due to The Incisors (Black arrows).

\section{Examination adult suspects}

Three adult suspects who may have inflicted the bite marks on the child were brought to the Dental Faculty of the University of the Western Cape for dental examination.

Written consent for the dental examination was obtained for each suspect. Examination of ZP (the complainant) showed that she had no upper teeth and this eliminated her as a possible bite perpetrator.

The suspect that was arrested (UP) was the first biting pattern to be analysed. A tracing of her biting pattern of her upper teeth was superimposed over the photograph of the bite mark of the left abdomen of the child (Fig. 4).

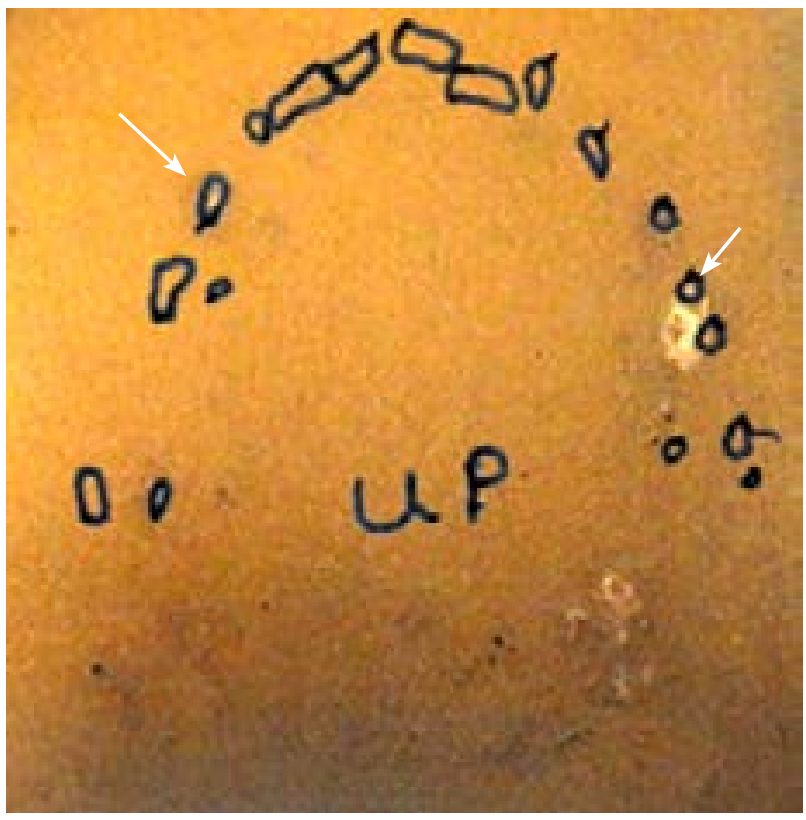

Figure 4. The tracing of the biting pattern of UP superimposed on the lesions of the bite mark.

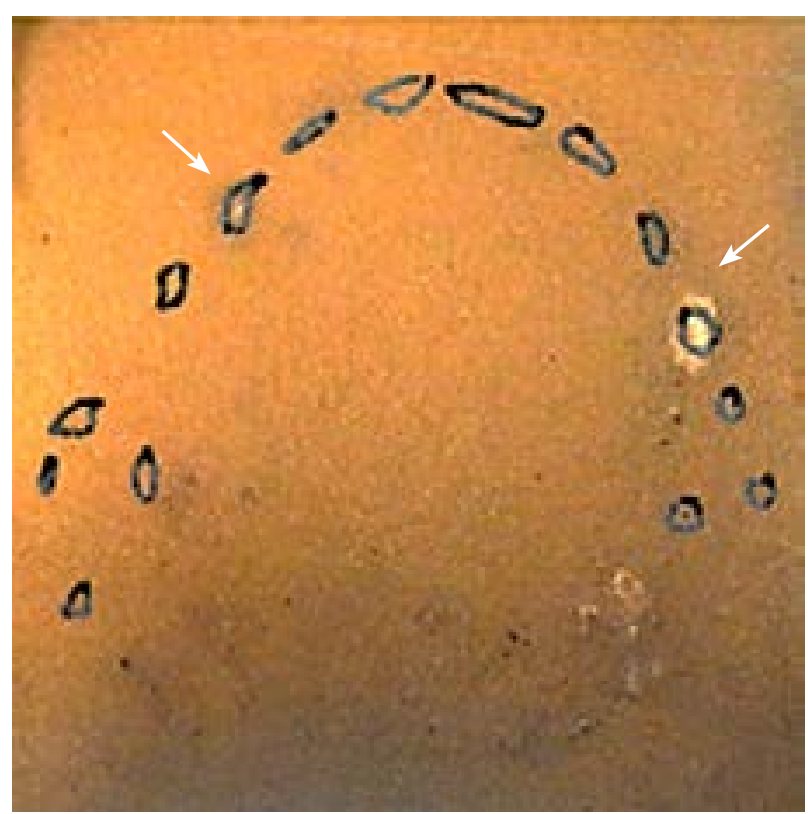

Figure 5. The tracing of GL's biting pattern of her upper teeth showed an accurate match with the bite mark. 
When the left canine is placed on the puncture wound the right $1^{\text {st }}$ premolar almost overlays the right puncture wound. This showed a possible correlation and that the bite mark could have been inflicted by UP's upper teeth.

The biological mother GL was examined and the tracing of her biting pattern was superimposed over the photograph of the bite mark (Fig. 5). There was an accurate alignment of her upper teeth with the bite mark on the child.

The third suspect GE only had two maxillary canines and his dental arch was much narrower than the bruise pattern of the bite mark.

\section{DISCUSSION}

Bite marks are associated with an oval pattern of bruises or puncture wounds on the skin of the victim. These lesions are due to the force of the biting surfaces of the upper and lower teeth into the skin of the victim.

The degree of definition of a bite mark is dependent on the force with which the bite is inflicted. The analysis is dependent on the time span between the biting of the victim and when the bite mark is examined. The longer the time span the less distinct the bruises because healing of the bite mark lesions takes place.

The skin is a malleable medium and is subject to distortion when a force is applied. This is the reason that bite mark analysis is not an exact science, but an adjunct in the forensic analysis of trauma.

The method of analysis of bite marks depends on the matching of the biting pattern of the suspect with a $1: 1$ photograph of the bite mark being investigated. Ideally the bite mark would show the bruises caused by the upper and lower anterior teeth in an oval or curved pattern.

In this case healing of the superficial lesions had taken place leaving only the distinct puncture wounds due to the canines or first premolar teeth. The examination of the bite marks on the body of the child took place approximately three weeks after the assault.

The time span resulted in poor definition of the bite marks for comparison purposes because healing of the lesions had occurred.

One of the bite marks, however, showed distinct puncture wounds. This bite mark, situated on the left abdomen of the child, was used to investigate the biting patterns of the three suspects by the superimposition of their biting patterns of their upper teeth over a 1:1 photograph of the bite mark.

The results of the analysis of the biting pattern of UP's upper teeth with the bite mark showed that she may have bitten the child. Her dental arch of her upper teeth, however, show a slightly wider arrangement of the teeth (Fig. 4) compared with the puncture wounds and the position of the upper right teeth did not match the bite mark accurately enough. There is a moderate degree of probability that UP inflicted this bite mark on the child.

The analysis of the biting pattern of GL's upper teeth with regard to the bite mark showed that the dental arch of her upper teeth matched the puncture wounds. The upper left canine tooth and the upper right canine and $1^{\text {st }}$ premolar teeth matched the puncture wounds (Fig. 5).

\section{CONCLUSION}

The results of the analysis of the biting patterns of the three suspects showed that the most likely person to have inflicted the bite on the left abdomen of the child was her biological mother GL. Her biting pattern matched the bite mark accurately. There was a high degree of probability that the perpetrator of the bite mark on the abdomen of the child was inflicted by the child's mother (GL).

\section{Declaration}

No conflict of interest declared.

\section{References}

1. Thompson, I.O.C., Phillips, V.M. Bite mark case with a twist. The Journal of Forensic Odontostomatology, 1994; 12: 37-40.

2. Phillips VM, Van der Heyde Y. Oro-facial trauma in child abuse fatalities. South African Medical Journal. 2006. 96; (3): 213-5.

3. V M Phillips. Bite marks on the finger of a male and the hand of a female suspect in a murder case. A case prepared for presentation for the inquest in Cape Town High Court. 2011. 